
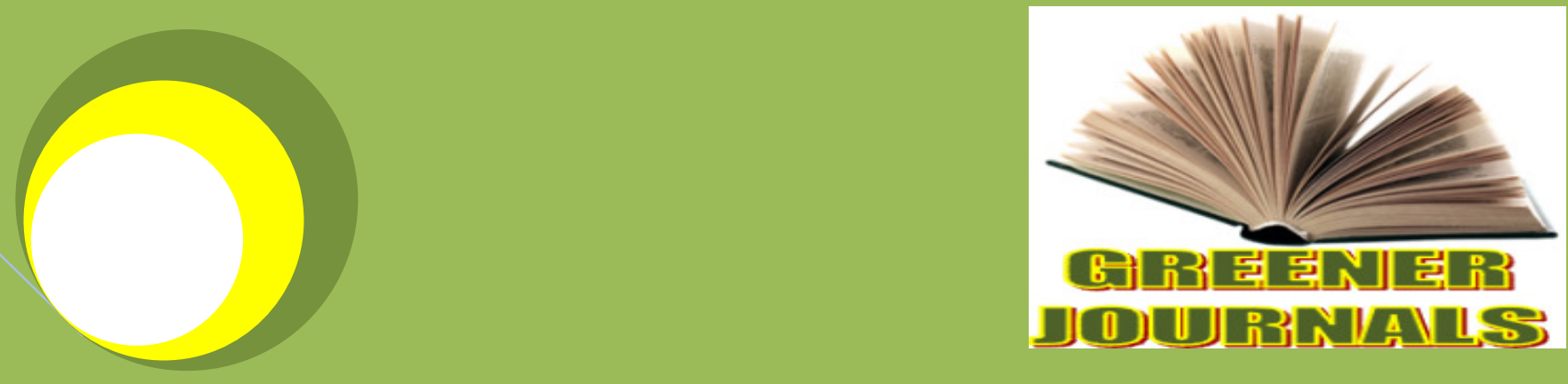

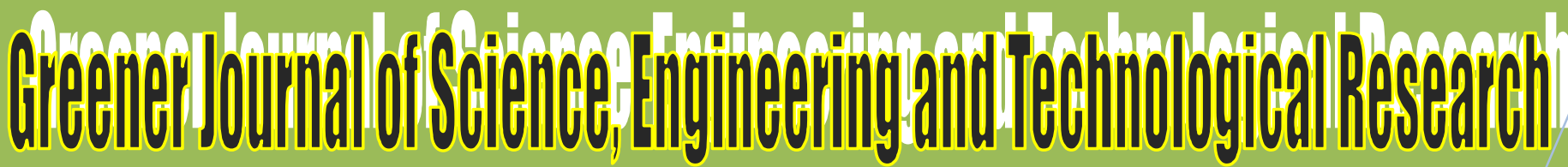
ISSN: 2276-7835 Impact Factor 2012 (UJRI): 0.7563 ICV 2012: 5.62

Studying Increase in Strength of Clays by Including Calcium Chloride Solution

By

Ataollah Abdollazadeh Afshin Sedaghat 


\title{
Studying Increase in Strength of Clays by Including Calcium Chloride Solution
}

\section{*Ataollah Abdollazadeh and Afshin Sedaghat}

\author{
Department of Civil Engineering, University of Guilan, Rasht, Iran. \\ *Corresponding Author's Email: maziyarniyakan@gmail.com
}

\begin{abstract}
Increase of mechanical strength of fine-grained soils has been considered by the researcher to achieve different goals and stabilize landslides. Use of Calcium Chloride Solution $(\mathrm{CaCl} 2)$ is a new method through which calcium chloride solution leaves free ion of calcium while passing through soil. Ion of calcium associates soil particles through Pozzolana reaction or by absorbing cation in double clay layer. In this paper, clay strengthening method and effect of the above solution on increase of mechanical strength of clay and improvement of its bearing capacity are studied by performing laboratory tests. A series of clay sample was prepared as a rectangular cube with grading and given density. The samples were affected by calcium chloride solution with different concentrations for definite term with hydraulic gradient of $10 \%$. After determining conductivity of soil which is equal for all samples, strengths of each sample were measured.
\end{abstract}

Key words: Calcium Chloride, soil stabilization, cohesion, internal friction angle, Normality.

\section{INTRODUCTION}

Increasing resistivity of fine-grained soils always has been desirable to achieve various purposes. For this aim, Calcium ion has been used in the form of lime to make soils resistant. Soil modification by lime takes place through chemical reactions of cementation and cation exchange [1]. According to reports presented by Davoudi et al (2008) and Ahmadali (2007), use of saturated lime solution is a newer and more effective method because it provides free calcium ion for soil $[2,3]$. But using saturated lime solutions is not devoid of problems. One of these problems is low solubility of lime, $0.137 \mathrm{gr}$ per $100 \mathrm{gr}$ water (Shah nazari, 1997) and the other is possible harmful reactions which may occur in the soil. The most important harmful reaction is Carbonation. This reaction occurs when high amount of lime is added to the soil or there is not enough clayey soil to absorb lime. In these circumstances, excess lime reacts with $\mathrm{CO}_{2}$ present in air and $\mathrm{CaCO}_{3}$ is formed. Another harmful reaction of lime is formation of ettringite causing a reduction in soil resistivity and development of more swell. This reaction occurs when lime is combined with clay minerals and sulphate present in the soil or the soil is exposed to water having sulphate. Therefore it is recommended to use calcium chloride because of its high solubility, i.e. $74 \mathrm{gr}$ per $100 \mathrm{gr}$ water does not lead to environmental problems. Calcium chloride can be a good alternative for lime.

The presence of a hydraulic gradient causes fluids to flow inside the soil. Use of calcium chloride is a new method during which calcium chloride solution passes through the soil and leaves free calcium ion in the soil. As calcium ion enters the soil and comes into contact with soil colloids, it is activated or enters clay double layer through pozzolanic reaction or cation absorption. This causes soil particles to join each other and consequently soil mechanical resistivity to increase [8]. Free chloride ion also enters the soil and somewhat reduces its permeability [7].

Studies performed by Davoudi and Kabir showed that calcium-sodium silicate gels improve the cementation faster than a calcium silicate gel. They also found that the positive influence of the salt on the soil containing lime is more significant when percentage of lime is low. Generally this method results in improvement of bearing capacity and shear resistance parameters [9].

\section{MATERIALS AND METHODS}

The soil used in this study is classified as low plasticity clay (CL) soil according to the unified classification system. Liquid limit, plastic limit, optimum moisture and maximum dry specific weight for the soil used in this study are equal 
to $28 \%, 17.5 \%, 13.5 \%$ and $1.885 \mathrm{gr} / \mathrm{cm}^{3}$, respectively. The studied soil contains $25 \%$ clay, $22 \%$ silt and $53 \%$ sand. Calcium chloride used in this study is white, powdery or granular calcium chloride white with grain size of 2 to $6 \mathrm{~mm}$, which is available in $1 \mathrm{kgr}$ packets. Calcium chloride specific weight and molar mass are equal to $2.15 \mathrm{gr} / \mathrm{cm}^{3} \mathrm{and}$ $110.98 \mathrm{gr} / \mathrm{mol}$, respectively. Its solubility is $740 \mathrm{gr}$ per liter water at temperature of $20^{\circ} \mathrm{C}$.

Gradation, Atterberg limits, Proctor standard and direct shear tests were performed according to standards ASTMD698, ASTM-D3080, ASTM-D421 and ASTM- D4318, respectively.

For making samples, the soil was initially rolled to reach a reduction of $13.5 \%$, the same as optimum moisture. Then the soil compacted in three layers within boxes prepared with dimension of $11 \times 30 \times 10 \mathrm{~cm}^{3}$ to reach $90 \%$ compaction. To avoid swell and soil expansion during passage of solution flow, an excess load equal to $1 \mathrm{kPa}$ was applied on sample surface. The required amount of calcium chloride was solved in water to prepare the desired solution.

The level of solution in the tank is kept constant using a Marriott pipette. In the nomenclature of samples, V represents the volume of the solution passed the soil which is constant and the number following it determines the concentration of calcium chloride in the solution.

In order to investigate the effect of concentration of calcium chloride solution, four similar samples are prepared and the same volume of solution, which is equal to 3 times volume of soil pores $(\mathrm{V}=4452 \mathrm{cc})$ is passed through the samples. Following concentrations were used in the experiments:

1) Normality of 0.33 equivalent to $18.3 \mathrm{gr}$ calcium chloride per one liter water

2) Normality of 0.66 equivalent to $36.6 \mathrm{gr}$ calcium chloride per one liter water

3) Normality of 0.99 equivalent to $55 \mathrm{gr}$ calcium chloride per one liter water

4) Normality of 1.2 equivalent to $73.2 \mathrm{gr}$ calcium chloride per one liter water

Simultaneous electrical, chemical and hydraulic gradients are conducive to emergence of various electrokinitic phenomena in the soil [6]. When optimum concentration is obtained, an experiment is performed at this concentration using electrokinetic methods to investigate the influence of this method on resistivity parameters of the soil. Kadivar and Davoudi's studies (2011) showed that optimum voltage for similar samples is 30 volts [5].

Firstly, solution is passed through the soil samples to become fully saturated. For passing the solution through the soil, a $10 \%$ slope is applied to the molds in the same direction as solution flow. Flow of the solution continues until the desired volume is achieved. Finally, three samples are separated from middle part of the mold containing untreated soil at three various depths. Each sample is stabilized by direct shear instrument for one hour and then drained direct shear test is performed at the rate of $0.2 \mathrm{~mm} / \mathrm{min}$ and with normal overloads of 25,50 and $75 \mathrm{kPa}$ until $10 \%$ displacement or peak resistivity is achieved. Figure 1 shows the sample through which only solution is passed and Figure 2 shows the sample through which both solution and electrical current are passed.

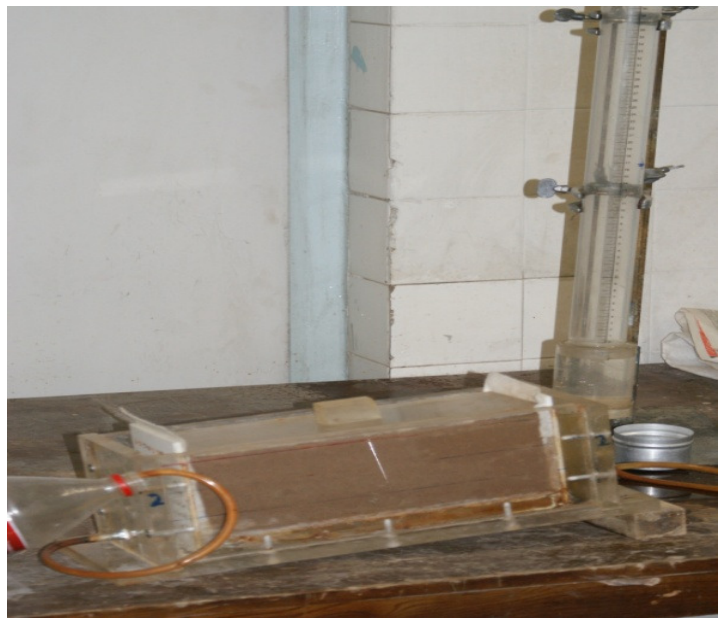

Figure 1. The sample through which only solution is passed. 


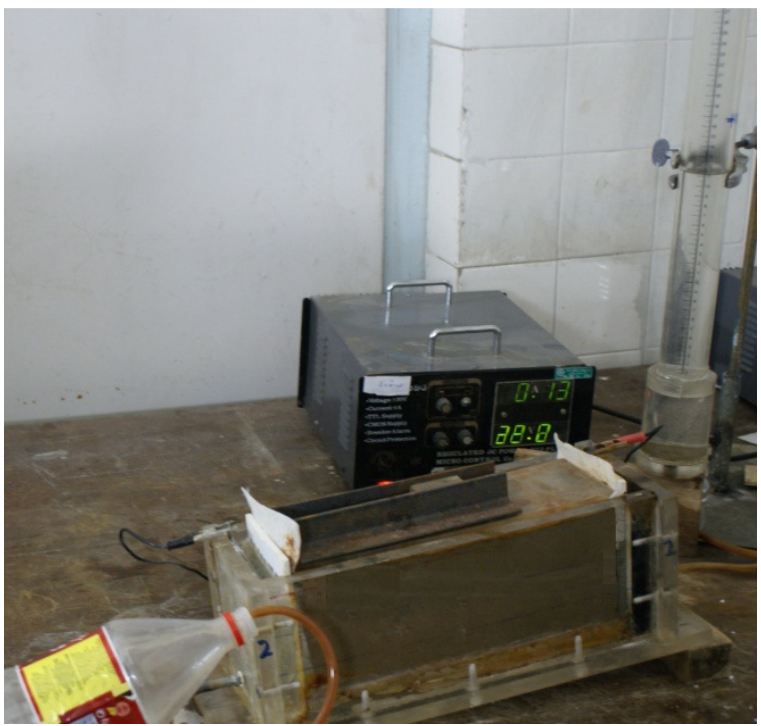

Figure 2. The sample through which both solution and electrical current are passed.

\section{RESULTS AND DISCUSSION}

Cohesion and internal friction angle parameters were calculated for untreated soil using direct shear test. These values are respectively equal to $2.1 \mathrm{kPa}$ and 23.7 degree. Figure 3 shows failure envelope for untreated soil.

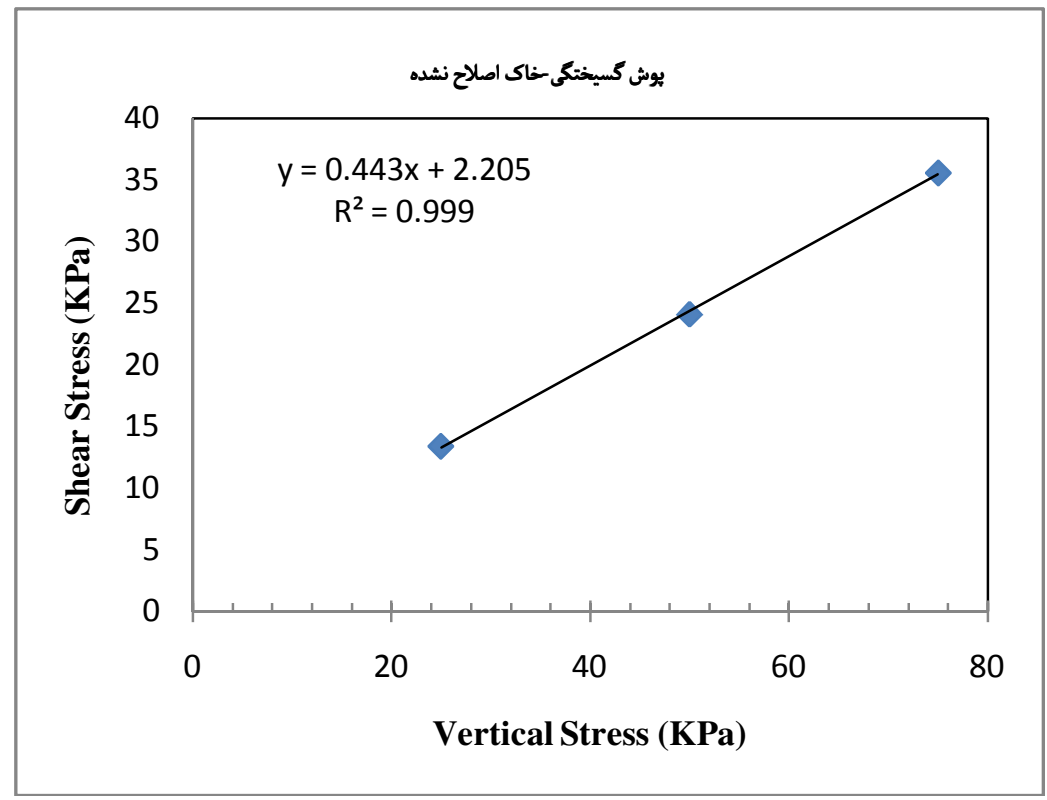

Figure 3. The failure envelope of untreated soil.

Figure 4 demonstrates stress-strain curve for different samples at normal stress of $75 \mathrm{kPa}$. 


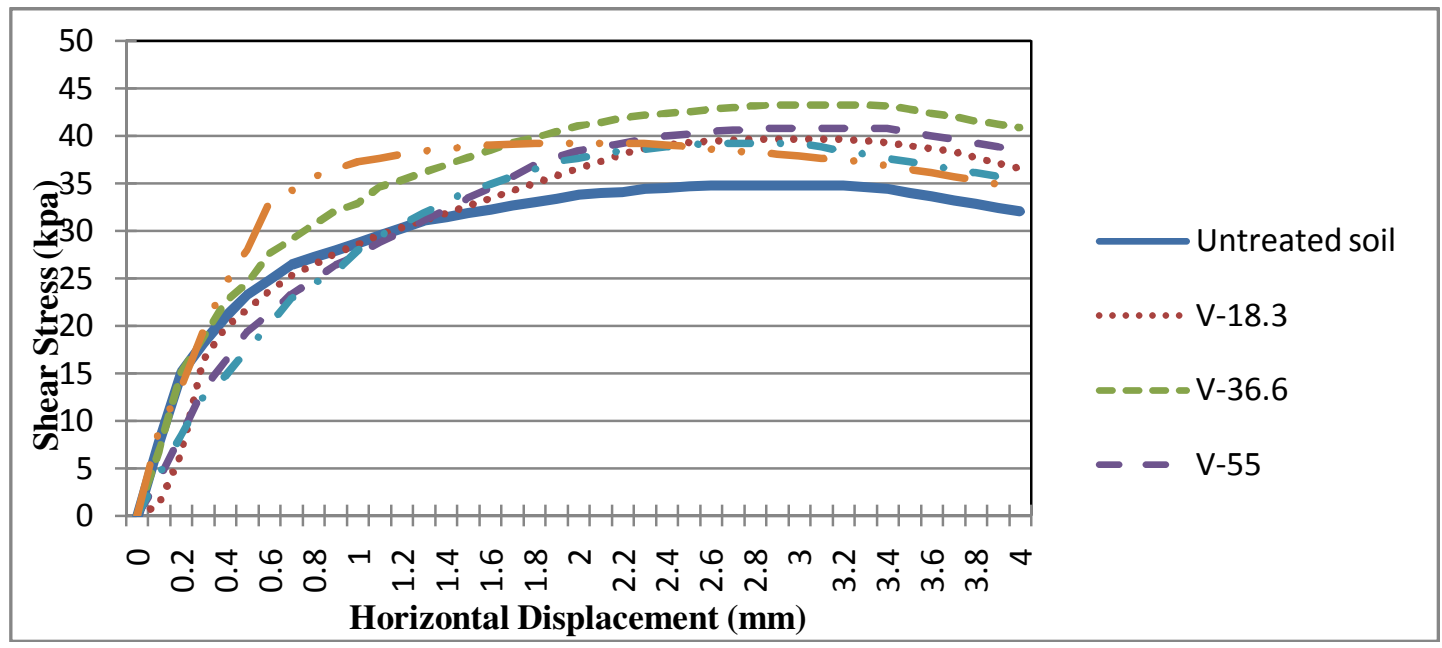

Figure 4. Stress-strain curve at normal stress of $75 \mathrm{kPa}$.

Failure envelop curves of soil samples can be plotted using maximum shear stress values obtained from stressstrain curves at different normal stresses. Failure envelops of all the samples are shown in Figure 5.

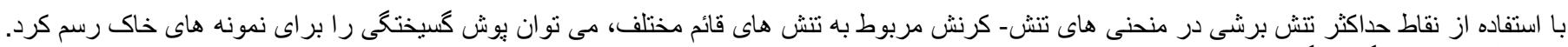

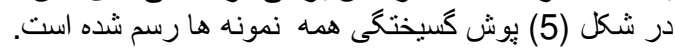

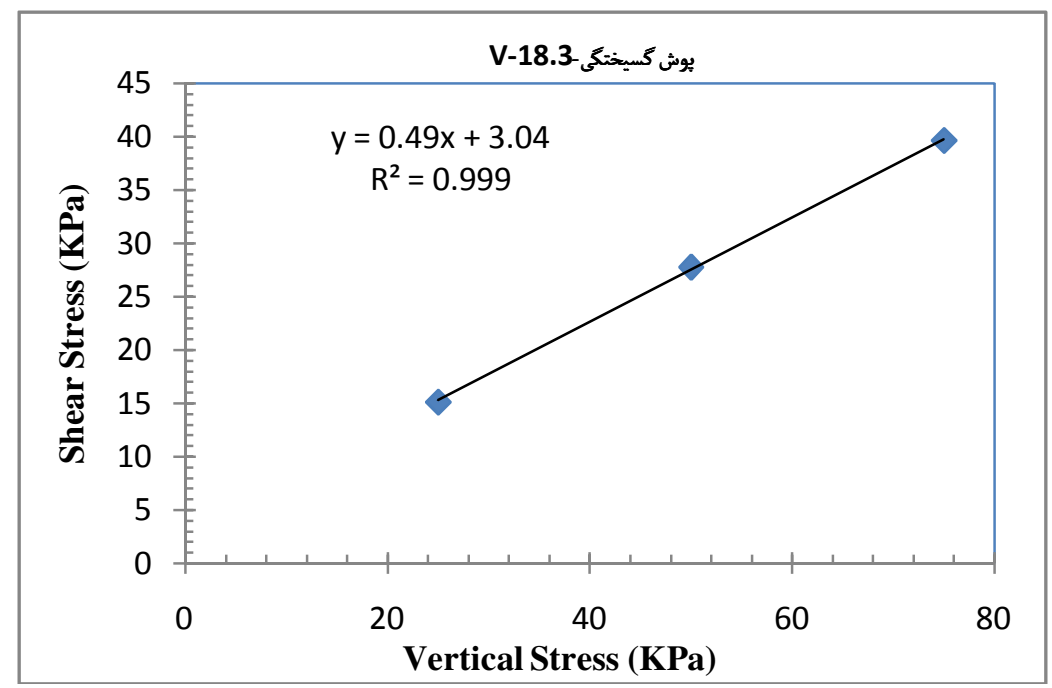



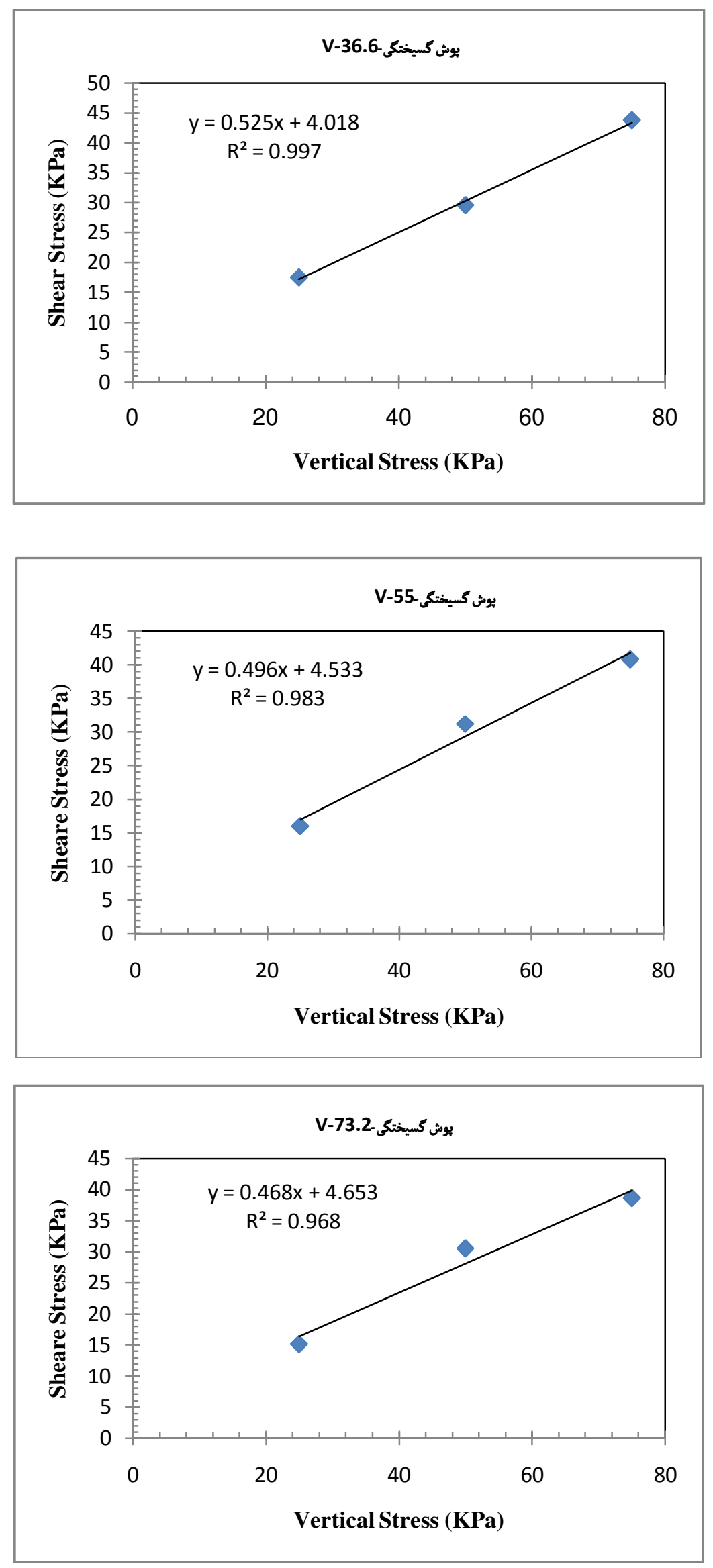


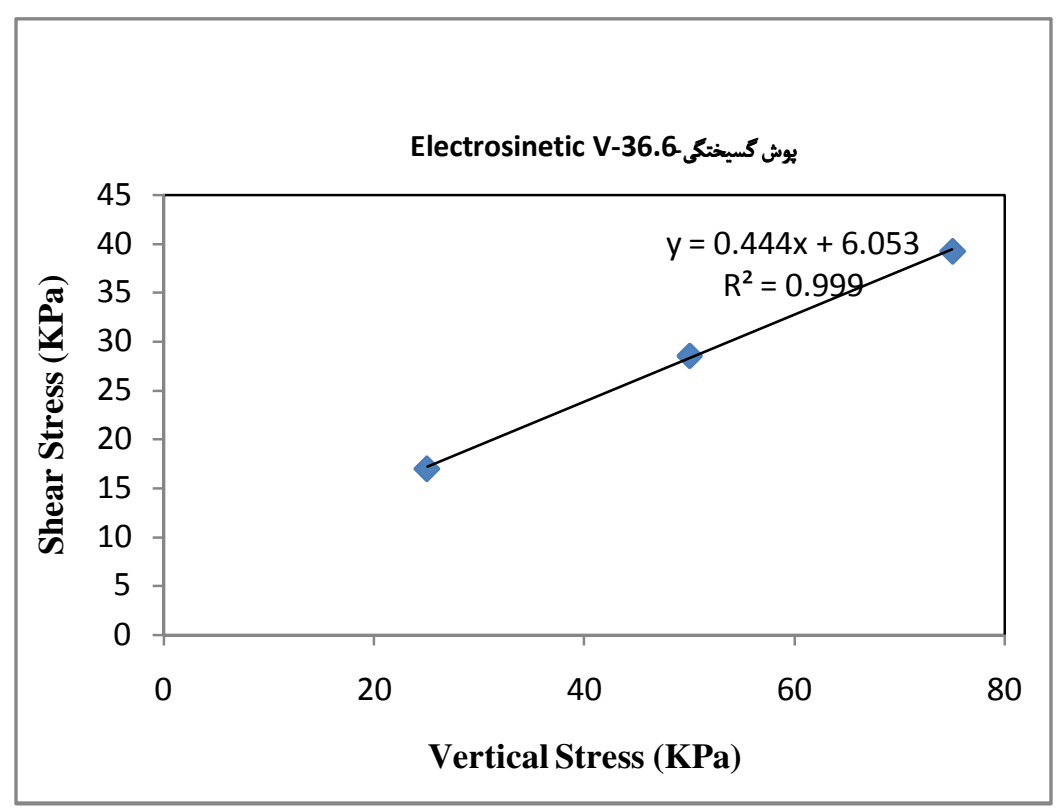

Figure 5. Failure envelops of treated samples.

In Table 1, the values of soil resistivity parameters, i.e. cohesion (C) and internal friction angle are listed. Comparison of the values reveals that soil cohesion and internal friction angle increases by $100 \%$ and $7.37 \%$, respectively using a calcium chloride solution with concentration of $36.6 \mathrm{gr} / \mathrm{lit}$.

Table 1. $\mathrm{C}$ and $\varphi$ values for various soil samples

\begin{tabular}{|l|l|l|l|}
\hline No. & Sample name & Cohesion $(\mathrm{kPa})$ & $\begin{array}{l}\text { Internal friction angle } \\
(\text { Degree })\end{array}$ \\
\hline 1 & Untreated soil & 2 & 23.6 \\
\hline 2 & V-18.3 & 3 & 26 \\
\hline 3 & V-36.6 & 4 & 27.7 \\
\hline 4 & V-55 & 4.4 & 26.3 \\
\hline 5 & V-73.2 & 4.7 & 25 \\
\hline 6 & V-36.6 electrokinetic & 6 & 24 \\
\hline
\end{tabular}

For better analysis, the percentage of rise in soil resistivity parameters is shown in Figure 6 for various samples. As it is observed, maximum increase is observed in sample V-36.6.

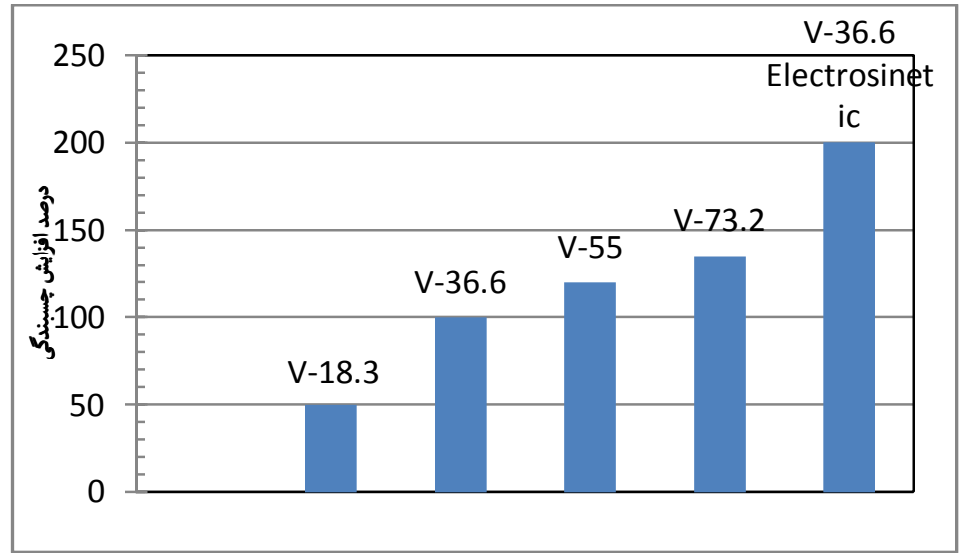




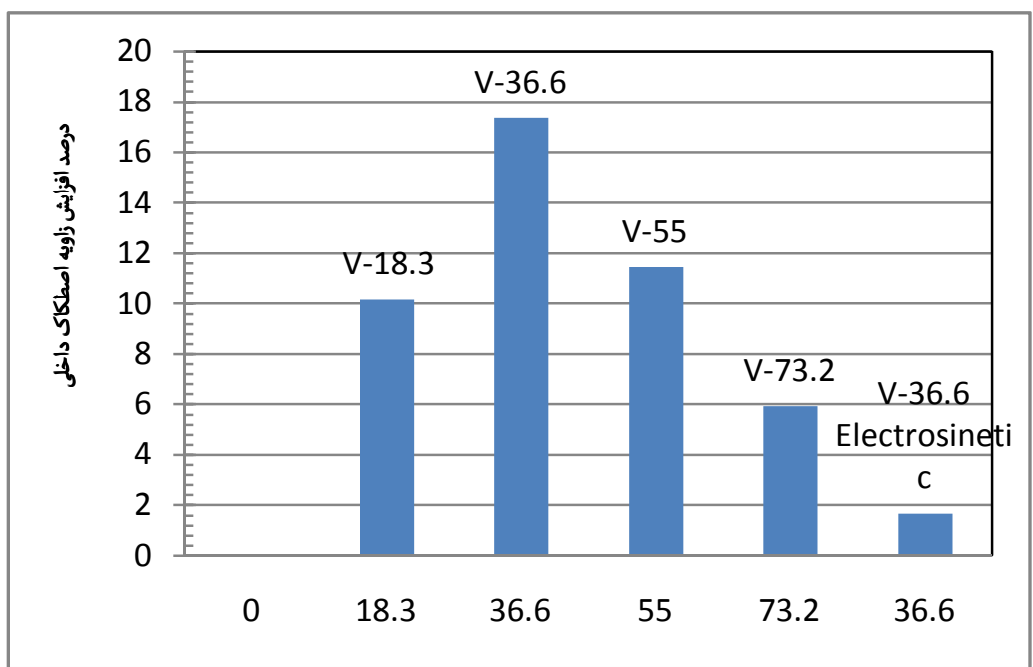

Figure 6. The amount of rise in resistivity parameters of the treated soil with respect to witness sample.

\section{CONCLUSION}

1. Obtained results suggest positive influence of calcium chloride solution on soil shear resistance such that maximum shear resistance increased $22.96 \%$ by passing $36.6 \mathrm{gr} / \mathrm{lit}$ calcium chloride solution.

2. Calcium chloride reduces soil deformations. In fact, the soil becomes more brittle.

3. The influence of calcium on cohesion is much more than its influence on internal friction angle. This is more apparent for the samples through which both calcium chloride and electrical current (30 V) are passed such that cohesion of treated soil increases about $200 \%$ while a negligible increases is observed in internal friction angle. This can be explained by mechanism of calcium reactions with the soil, i.e. cementation and pozzolanic reaction.

4. When electrokinetic method is used, electric current severely ionizes the solution and more free calcium ions are provided for the soil. On the other hand, as chloride ions oxidize in anode, i.e. entrance, ionic equilibrium is disturbed and the concentration of positive ions, i.e. calcium, increases. Therefore movement of calcium ions toward the soil enhances and the calcium absorption, its cohesion and consequently shear resistance increase.

5. Considering the desirable soil volume and compaction and optimum concentration of the solution, this method can be generalized for local improvement of soils.

6. Taking into the account that calcium chloride has high solubility, produces no environmental problems and positively influences soil shear resistance, it can be considered as a good alternative for lime.

\section{ACKNOWLEDGEMENT}

The authors would like to thank authorities of soil preservation and watershed institute allowing the authors to use their laboratory instruments.

\section{REFERENCES}

Alvandkouhi, H., (2007). Increasing soil shear resistance in a sliding natural deposit using sinks containing water and lime, M.Sc. thesis, soil and foundation mechanics department, Islamic Azad university, central Tehran branch.

Ahadiali, V., (2007). Stabilization of unstable deposits by adding saturated lime solution, case study: eastern Donbolid (دنبليد) deposit of Taleghan, M.Sc. thesis, Islamic Azad University, central Tehran branch.

Davoudi, M., Siavoshnia, M, Vahedi aali, V., (2008). Modification of swelling subgrades soil in irrigation networks and stabilization of sliding subgrades of water transmit channels using saturated lime solution, First Seminar on geotechnical issues of irrigation and drainage networks, P. 281-288. 
Bandehzade, A., Davoudi, M., Astaneh, M., (2010). Investigating influence of time and percentage of lime and fly ash mixture on physical and mechanical properties of fine-grained soils, Fourth international conference on Iran's geotechnical engineering and soil mechanics, Tehran, Iran, November.

Kadivar, M., Davoudi, M., (2011). Adding calcium ion to fine-grained soils to increase mechanical resistivity of the soils using electrokinetic method, sixth national conference of Civil engineering, Semnan, Iran, April.

Mitchell, J.K., (1993). "Fundamentals of Soil Behavior", John Wiley \& Sons, Inc, pp 229-270.

Fang, H., (2004) "Foundation Engineering Handbook," CBS Publisher \& Distributors, pp 350-351.

M. Dontsova, L.Darrell. Norton. (2004). Influence of Exchangeable cations on water Adsorption by soil clays.

M. H. Davoudi and E. Kabir (2010). Interaction of lime and sodium chloride in a law plasticity fine grain soils. 